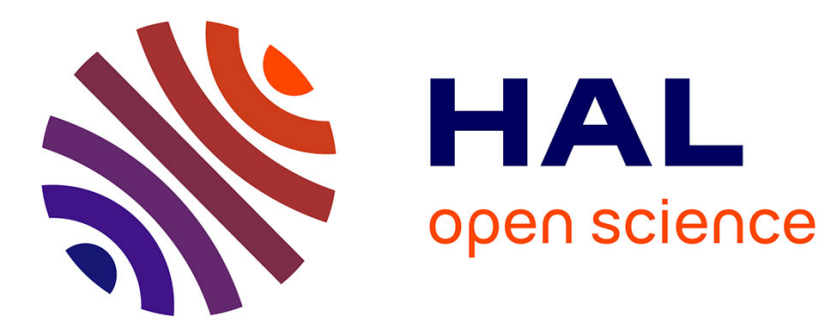

\title{
Meta-Standard for Collaborative BIM Standards: An Analysis of UK BIM Level 2 Standards
}

\author{
Mohamed Binesmael, Haijiang Li, R. Lark
}

\section{To cite this version:}

Mohamed Binesmael, Haijiang Li, R. Lark. Meta-Standard for Collaborative BIM Standards: An Analysis of UK BIM Level 2 Standards. 19th Working Conference on Virtual Enterprises (PRO-VE), Sep 2018, Cardiff, United Kingdom. pp.661-668, 10.1007/978-3-319-99127-6_57 . hal-02191183

\section{HAL Id: hal-02191183 \\ https://hal.inria.fr/hal-02191183}

Submitted on 23 Jul 2019

HAL is a multi-disciplinary open access archive for the deposit and dissemination of scientific research documents, whether they are published or not. The documents may come from teaching and research institutions in France or abroad, or from public or private research centers.
L'archive ouverte pluridisciplinaire HAL, est destinée au dépôt et à la diffusion de documents scientifiques de niveau recherche, publiés ou non, émanant des établissements d'enseignement et de recherche français ou étrangers, des laboratoires publics ou privés. 


\title{
Meta-Standard for Collaborative BIM Standards: An Analysis of UK BIM Level 2 Standards
}

\author{
Mohamed Binesmael, Haijiang Li, and R Lark \\ School of Engineering, Cardiff University, Queen's Building, 14-17 The Parade, \\ Cardiff CF24 3AA, UK \\ \{binesmaelm, lih, lark\}@cardiff.ac.uk
}

\begin{abstract}
The nascent journey of the AEC (Architecture, Engineering, and Construction) industry toward a fully collaborative BIM (Building Information Modelling) maturity has resulted in the development of siloed standards. Whilst some countries lead the charge in BIM maturity level adoption, other countries are pressed to develop their own policies to minimise stagnation. This results in the unintended fragmentation of the AEC industry globally, and further enlarging the international collaboration rift within multinational firms. This article analyses key BIM standards and policies adopted in the UK based on a published 3C Meta-Standard framework. The disparity between the standards towards the Industry Foundation Classes (IFC) specification goals are highlighted to recommend adjustments where necessary. A 34\% gap was found, particularly in the topic areas of object connectivity and the multiple disciplinary information capture. This study forms one of three key research elements in the pursuit of developing a dynamic and autonomous BIM platform, capable of delivering parameters between stakeholders involved in complex BIM projects.
\end{abstract}

Keywords: Meta-standard · Collaboration · BIM Cognitive System · Building Information Modelling · BIM · Industry Foundation Classes · IFC · BIMNet

\section{Introduction}

To develop a cognitive system within the AEC (Architecture, Engineering, and Construction) industry requires an understanding of the relationships between stakeholders, the tools these stakeholders use, the standards by which they abide, and the data points that will be captured. The purpose of a cognitive system in the AEC industry is to facilitate the adoption of collaborative versions of Building Information Modelling (BIM), and allow for collaboration between humans.

The research herein will focus at analysing the standards perspective as standards highlight the necessary interactions between stakeholders, challenging how a collaborative network is designed. To self-assess standards and identify 
gaps in the current standards requires a framework of standard assessment, hence the $3 \mathrm{C}$ meta-standard framework will be utilised in the methodology of this study.

The UK Government mandated that public projects must be working at BIM Level 2 since 2016 with the aim of reducing public sector asset costs. BIM Level 2 requires the capture of data and documents electronically for project and asset information, as well as the use of a Common Data Environment (CDE) across disciplines for the handling of 3D geometrical and non-graphical data [1].

To achieve BIM Level 3, full collaboration across all disciplines is the necessary requisite alongside a central, shared project model [1]. To achieve full collaboration, interoperability must be prioritised by data standards to make data accessible across all platforms [2]. A bottom-up approach is being explored to ensure all stakeholders can easily be involved in the process from the outset. The difficulty with construction projects is that stakeholders are never the same and the dynamic relationships and information exchanges required between stakeholders often vary. A cognitive system that is able to develop, learn, and keep track of relationships for projects to suggest the best information exchanges therefore requires investigation to determine if it may solve the industry's woes.

\section{Theory}

\subsection{State of the Art}

The oft-cited BIM wedge (Figure 1) developed by Mark Bew and Mervyn Richards [3] shows that the standards: BS 1992:2007, PAS 1992-2:2013, PAS 1992-3:2014, and BS 1192-4:2014 fall below the threshold to achieve BIM Level 3. This study will focus on analysing these four documents against a high-level breakdown for ISO 16739, which is one of five basic methodology standards developed by buildingSMART International. ISO 16739 outlines methods for exchange of relevant data through Industry Foundation Classes (IFC).

ISO 16739 was selected as the standard for testing the application of the $3 \mathrm{C}$ meta-standard framework, due to it being a key enabler to data interoperability. 


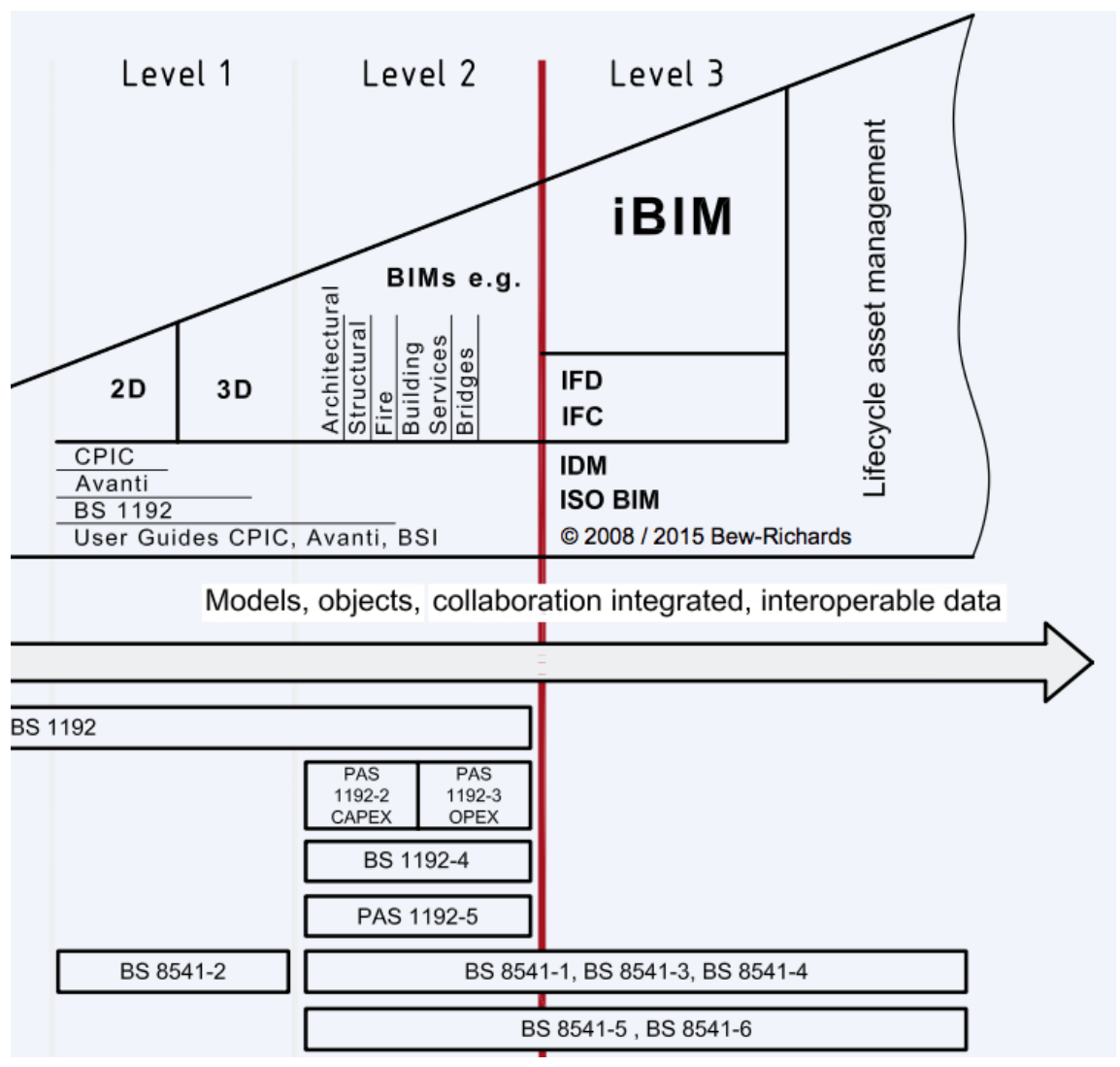

Figure 1 - BIM maturity levels (reproduced and cropped for detail from PAS 1192-5:2015)

The concept behind the methodology standards is to create a new digital language that is open and allows for structured information to be freely exchanged [4]. The goal of open standards is to steer industry towards collaboration and information exchange away from proprietary software, and therefore requires standardisation as a prerequisite [5]. The adoption of such standards can be further intensified through the effect of network technology, whereby the utility of users increases when another user adopts the standard [6]. A cognitive system that works in collaboration between people from all disciplines and software would instil this network technology across all stakeholders.

The UK is leading the charge in clearly defining standards and Publicly Available Specifications (PAS) required to achieve BIM Level 2. Countries worldwide are developing similar but incomplete mandates, such as a 10-part series for the VDI 2552 in Germany; one published, two draft documents, and seven as ongoing projects. American standards are fragmented nationally across states, 
making it difficult to include them in the study scope. Norway leads in case studies of BIM adoption to high levels, however the mandate between levels is kept vague.

This is an extensive list; therefore, the scope of this study is focusing on creating a $3 \mathrm{C}$ meta-standard framework to analyse the relevant UK BIM Level 2 documents, with the hope that future work can refine the framework process.

\subsection{BIMNet Platform}

Research at Cardiff University is underway to study the requirements of a cognitive system able to collaborate between processes, objects, and people under the envelope of standards. The application of this system will be first applied to the IFC for ports and harbours project which is one of five extensions underway of the IFC schema for infrastructure, as the current IFC schema focuses on buildings.

This study paves for the way for a standard net that interlinks standards. Next must be the analysis of relationships between stakeholders captured by a data exchange net. The knowledge utilised by these stakeholders will also need to be captured as a knowledge net. These nets interweave to form the BIMNet platform.

The BIMNet will be a cognitive platform for collaborative BIM, allowing stakeholders to know what information is available to them and what information is still required from them, as well as allowing them to make requests on information. Other stakeholders can be informed by the system to contribute missing information. The understanding of relationships between stakeholders is key, and the standard net is the first item needed to obtain this understanding of relationships.

\subsection{C Meta-Standard Framework}

The 3C meta-standard is an architecture that allows for a standard to be broken down into its constituent components arranged in a matrix by competencies against capabilities [7]. The novelty in this study is that rather than applying the architecture to assess a company's conformity to the standard, the architecture is assessing other standards mandated against the high-level breakdown of the contemporary concept. The ISO 16739 is a qualitative standard rather than a quantitative standard as it is a management standard of how information is exchanged between parties; in contrast to a collection technical requirement.

Whilst ISO (International Standards Organisation) primarily creates technical standards, by adopting a Plan-Do-Check-Action cycle within buildingSMART in the approach to developing open standards, an ISO Management System Standards (MSS) is being invoked [7].

With the ISO being de jure, as a standardisation group is taking charge in encouraging open BIM standard adoption across the industry, the $3 \mathrm{C}$ meta-standard 
framework can be applied to ISO 16739. De jure standardisation is standards officially issued by chartered standards bodies and is a deliberate unification by intellectual means [8]. This is in contrast with de facto standards, which are driven by industry practices or dominating vendors and can sometimes be referred to as proprietary [7]. The nature of ISO 16739 makes it not vendor specific.

A multi-pronged approach to standard creation taking the best of both worlds could be achieved using PAS referenced in formal standards to allow for leading the market and quick adoption [9].

\section{$3 \quad$ Methodology}

The decision to analyse the UK BIM level 2 mandated documents was due to the EU approach to standardisation favouring development for interoperability over the USA approach which favours proprietary technologies [7], as well as clearly highlighted documents that pertain to BIM Level 2 adoption as a starting point. This makes the BIM Level 2 documents a good pilot for testing the $3 \mathrm{C}$ metastandard approach as the UK aims for interoperability with BIM Level 3.

Whilst the BIM Level 2 suite of documents refers to eight documents to follow, only four were pertinent to the analysis. PAS 1192-5:2015 complements these four documents (listed in chapter 2.1) however focuses on the security element of data exchange, and PAS 1192-6:2018 layers on top of the four documents to discuss exchange of health and safety information for construction sites. Both are not in the scope of ISO 16739. The remaining documents (BS 8536-1:2015 and BS 85362:2016) make multiple references throughout their text to refer to the 4 documents listed prior.

\subsection{C Meta-Standard Framework Terms}

The $3 \mathrm{C}$ meta-standard relies upon data to inform performance in the area being studied by the standard [7]. In this study this data is the evidence brought by the statements made within the BIM Level 2 documents.

The 3C meta-standard creates components by reformulating the standard statements into questions posed. These questions are placed within a matrix with the $\mathrm{x}$-axis describing the competency to which it belongs, i.e. the "topics addressed and accounted by the standard" [7]. The y-axis of the matrix describes the capabilities of the standard, i.e. what is "analysed and assessed by the standard" [7].

Capabilities are further subdivided into a sub-taxonomy which contains three sub-subjects: 
1. The need - the opportunity raised by the component,

2. The strategy - the approach introduced by answering the component,

3. The recommendations - how to achieve the target through the advice and directions provided by answering the component.

A final functionality termed Linkages, collects references made to other standards. The supra taxonomy consists of the components, competencies, and capabilities.

As this study is not focusing on developing a self-certification scheme, organising information by their properties and relations of data and knowledge is therefore not wholly required for this exercise [7]. This may be an approach that requires revision for analysing all national standards related to collaborative BIM.

\subsection{C Meta-Standard Framework Process}

A process for developing the matrix had not been described in the referenced paper. The process followed for this study began by outlining all the necessary competencies in the x-axis. This was relatively simple to follow as it allows for the chronological completion of the standard.

Once the competencies were complete, a chronological approach was taken to reformulate each competency area into questions. These questions formed the components that filled the matrix intersecting with each newly introduced capability recommended by the standard. If a capability within the competency being analysed referred to another competency, a new component at the intersection of the capability and that competency was created.

This approach allowed for an organic growth of the matrix without backtracking through the standard or missing out components. Iterations of capability ordering were required at times to allow for visually connecting them. 


\section{Results}

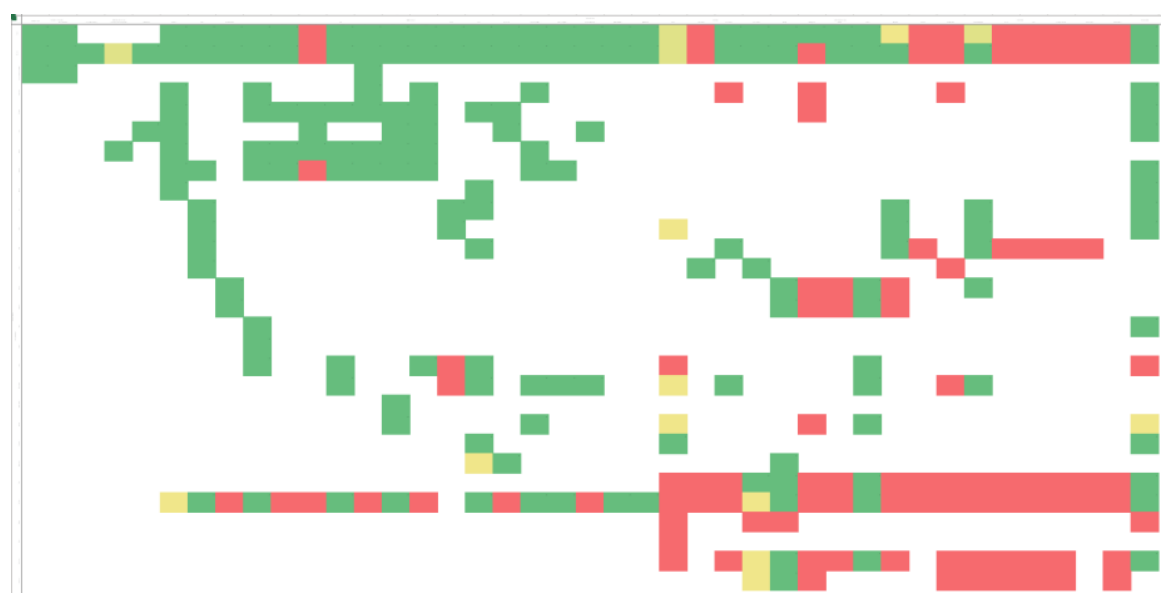

Figure 2 - Analysis of BIM Level 2 documents conforming to ISO 16739 3C Meta-

Standard Framework Architecture.

Green indicates at least one BIM Level 2 document adheres to the component.

Lime green/yellow indicates at least one BIM Level 2 document partially adhering to the component.Red indicates no BIM Level 2 document adhering to the component.

The high-level breakdown of ISO 16739 resulted in the development of 41 competencies, measured by 29 capabilities, and 292 components intersecting the two axes (Figure 2). These 292 components were applied to each of the four BIM level 2 documents being analysed. The analyses of the developed $3 \mathrm{C}$ meta standard against the four BIM Level 2 documents resulted in the majority of the components being addressed (Figure 2). Components not addressed by these standards primarily included object connectivity and interdisciplinary topics.

A detailed look at the components in

Figure 3 shows how the standard is reformulated as a matrix of closed questions to allow for simple self-evaluation. Once answered, the colour of the boxes automatically changes to create what's seen in Figure 2 . 


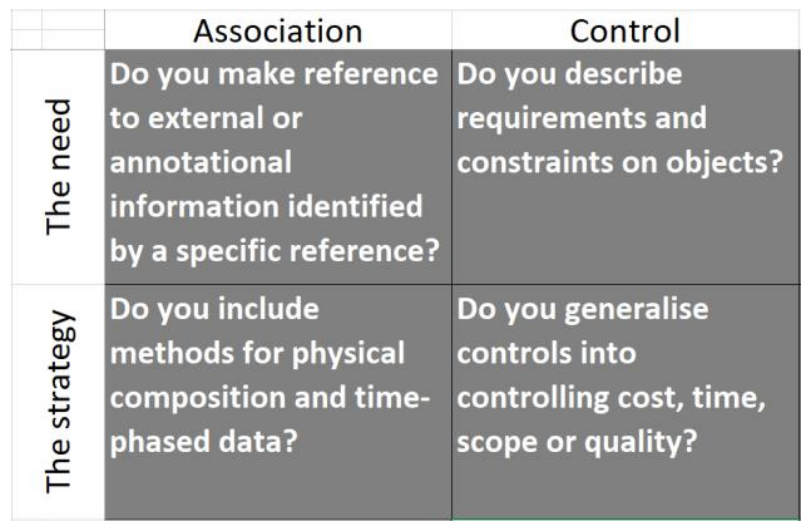

Figure 3 - 3C Meta-Standard Framework Architecture: Detailed look at four components developed for ISO 16739. The upper axis forms the competencies, the left axis highlights the capabilities, with the intersection of the two forming the competency.

Table 1 further divides the analysis into the separate document analyses that were conducted. It can be seen that BS 1992-4:2014 contributes the majority of the components, covering at least $50 \%$ of the IFC specification. In total, it could be said that if a user adhered to the BIM Level 2 documents that they would be attaining $66 \%$ completion towards a collaborative BIM environment.

Table 1 - Analysis of each of the four BIM level 2 documents independently and the overlapping total for 292 components in the matrix.

\begin{tabular}{|l|r|r|r|r|r|r|r|}
\hline Standard Name & \multicolumn{1}{|c|}{ Yes } & \multicolumn{1}{|c|}{ Partial } & No & Linkages & $\%$ Yes & $\%$ Partial & $\%$ No \\
\hline BS 1992 2007 & 26 & 6 & 260 & 2 & $9 \%$ & $2 \%$ & $89 \%$ \\
\hline BSI PAS 1192-2 2013 & 90 & 13 & 189 & 3 & $31 \%$ & $4 \%$ & $65 \%$ \\
\hline BSI PAS 1192-3 2014 & 47 & 6 & 239 & 2 & $16 \%$ & $2 \%$ & $82 \%$ \\
\hline BS 1192-4 2014 & 146 & 12 & 134 & 1 & $50 \%$ & $4 \%$ & $46 \%$ \\
\hline Total Overlapping & 178 & 14 & 100 & 8 & $61 \%$ & $5 \%$ & $34 \%$ \\
\hline
\end{tabular}

$B S$ 1192:2007 covers the least out of the four documents analysed. This is not surprising as it predates the IFC4 specification which is the 2013 version of ISO 16739.

PAS 1192-2:2013 was a big leap in the number of components considered, which focused on information exchange for contracts, as well as responsibilities of actors. However, there was a lack of focus on objects and interoperability. The primary focus of this document covered the association and control competencies.

PAS 1192-3:2014 focused on the operation and management of assets and so contributed little to the IFC related elements.

BS 1192-4:2014 introduced COBie (Construction Operations Building information exchange) which dealt with many of the components raised by the IFC 
specification, from level 1 projects to a potential role within integrated BIM (UK Level 3), including some IFC entities.

\section{$5 \quad$ Discussion and Conclusion}

The 3C meta-standard framework is an engaging method of evaluating components of a standard. It simplifies the standard to a set of questions that users are required to answer through validating statements. The nature of the framework lends itself to self-validation and self-evaluation. Validation would require an expert panel workshop to discuss the developed matrix and compare answers.

Whilst most of the BIM Level 2 documents are PAS, the PAS process enabled the specification to rapidly be developed to fulfil the immediate need in the AEC industry. PAS 1192-2:2013 provided a leap in bringing on board the recommendations of ISO 16739. The development of BS 1192-4:2014 as a British Standard was a good for leaping the industry toward the collaborative BIM vision. The gap remains in connecting all the disciplines as can be seen by the results. Whilst most of the capabilities were covered by the documents, the object connectivity and domain schema competencies lacked exposure. This allows for a BIMNet cognitive system to connect objects between the stakeholders of the various disciplines outlined in the domain schemas.

Future work will investigate applying the 3C meta-standard to other international and national standards such as Germany, China, and USA. Furthermore, a suite of 3C meta-standards could be developed for the remaining four basic methodology standards that cover processes, the mapping of terms, workflow coordination, and process translation, with linkages between them. Feedback for this study however is crucial to ensure further research is progressing in the right direction so that the BIMNet platform develops the right cognitive system for the AEC industry. The research question sought to analyse the mandated BIM Level 2 documents against ISO 16739 which outlines the IFC specification for information exchange. A $34 \%$ gap was found, particularly in the topic areas of object connectivity and the multiple disciplinary information capture that is necessary if future collaboration for a BIM Level 3 system is to take place. This gap allows for a cognitive system such as the BIMNet platform outlined in this study to take hold.

\section{References}

[1] BSI, "FAQs | BIM Level 2.” [Online]. Available: http://bim-level2.org/en/faqs/. [Accessed: 20-Apr-2018]. 
654 M. Binesmael et al.

[2] Institution of Civil Engineers, "State Of The Nation 2017: Digital Transformation," 2017.

[3] BSI, "PAS 1192-5: 2015: Specification for security-minded building information modelling, digital built environments and smart asset management," 2015.

[4] BuildingSMART International, "Open Standards - the basics - buildingSMART," 2018. [Online]. Available: https://www.buildingsmart.org/standards/technicalvision/open-standards/. [Accessed: 20-Apr-2018].

[5] J. West, "Seeking open infrastructure: Contrasting open standards, open source and open innovation," in First Monday, 2007.

[6] T. Heinrich, "Standard wars, tied standards, and network externality induced path dependence in the ICT sector," Technol. Forecast. Soc. Chang., vol. 81, pp. 309-320, 2014.

[7] sa Marsal-Llacuna, "The standards evolution: A pioneering Meta-standard framework architecture as a novel self-conformity assessment and learning tool," Comput. Stand. Interfaces, vol. 55, pp. 106-115, 2018.

[8] R. Patzke, H. Schumny, and N. Zisky, "Standardization aspects," Comput. Stand. Interfaces, vol. 19, pp. 249-256, 1998.

[9] A. V Stokes, "Who will standardise the standardisers: an analysis of the evolution of the standards-making process," Int. J. Med. Inform., vol. 48, pp. 61-65, 1998. 